\title{
ENSINO DE EMPREENDEDORISMO: ANÁLISE DA INTRODUÇÃO DE NOVAS PRÁTICAS EDUCACIONAIS EM UM CURSO SEQUENCIAL DE EMPREENDEDORISMO E INOVAÇÃO
}

\section{ENTREPRENEURSHIP EDUCATION: AN ANALYSIS OF THE INTRODUCTION OF NEW EDUCATIONAL PRACTICES IN AN ENTREPRENEURSHIP AND INNOVATION COURSE}

\author{
OLIVEIRA, Lana Cristina \\ lanacoliveira@yahoo.com.br \\ MARIANO, Sandra Regina Holanda \\ sandramariano@id.uff.br \\ UFF - Universidade Federal Fluminense
}

\begin{abstract}
RESUMO O objetivo deste estudo foi analisar as práticas educacionais adotadas para o ensino de empreendedorismo, tomando como objeto de análise um curso sequencial de Empreendedorismo e Inovação que incorporou novas práticas educacionais visando a aumentar a retenção e a aprendizagem dos estudantes. Para tanto, foram realizadas entrevistas com os profissionais responsáveis pela elaboração e implementação das novas práticas educacionais. A análise foi subsidiada pelo modelo proposto por Nunes et al. (2015), por meio do qual foram identificadas as limitações e potencialidades das práticas inseridas no curso. Trata-se de uma pesquisa exploratória, com abordagem qualitativa. Os resultados apontam que as novas práticas pedagógicas inseridas no curso analisado atendem a maioria dos indicadores, e destaca aspectos que ainda necessitam ser explorados.
\end{abstract}

PALAVRAS-CHAVE: Avaliação de práticas educacionais; Educação empreendedora; Inovação na educação.

ABSTRACT The purpose of this research was analyzed educational practices adopted at entrepreneurship teaching considering as object of analysis a sequential entrepreneurship and innovation course, which has incorporated new educational practices aiming increase the students retention and knowledge. Therefore, the professionals involved in the new educational practices preparation and implementation have been interviewed. The analysis was conducted through the suggested model for Nunes et al. (2015), wherewith it was identified the practices limitations and potentialities in the program. This is an exploratory research with a qualitative approach. As a result, new pedagogical practices in the program have covered most of the indicators and point aspects that still need to be searched.

KEYWORDS: Educational practices evaluation; Entrepreneurship education; Innovation in education.

\section{INTRODUÇÃO}


De acordo com Nunes et al. (2015) a qualidade da educação no Brasil, de maneira geral, tem resultados insatisfatórios em todos os níveis. Na educação básica, o Brasil figura entre as últimas posições no teste PISA, que mede conhecimentos de matemática e linguagem de jovens de 15 anos (PISA, 2017). No ensino superior, nenhuma universidade brasileira está posicionada entre as 100 melhores do mundo (INCE et al., 2017).

Um dos quadros preocupantes, também considerado crítico, constituindo um desafio para os envolvidos no processo educacional, é a existência, nos dias de hoje, de escolas semelhantes às do século XIX, onde atuam professores formados no século XX, cujos alunos são nascidos no século XXI (DESCHAMPS; CALEGARI, 2015).

É necessário que a escola seja capaz de acompanhar as mudanças ocorridas no mundo para que possa formar cidadãos conscientes e com capacidade de enfrentar os desafios que encontrarão em suas vidas adultas. Faz-se necessário, portanto, repensar o fazer escolar incluindo espaços, currículos, práticas e relações (DESCHAMPS; CALEGARI, 2015).

Na visão de Hinckel (2015), pensar a educação nos dias de hoje envolve pensar o processo de ensino-aprendizagem de modo mais dinâmico, inovador e contextualizado. Já para Nunes et al. (2015) algumas iniciativas no âmbito da educação apontam para a possibilidade de transformação da atual situação, para que a educação no Brasil passe a obter melhores resultados relativos ao nível de aprendizagem dos alunos, bem como a redução da evasão escolar.

O ensino do empreendedorismo também está inserido em debates sobre inovação em sala de aula no Brasil e no exterior. Em 2005, por exemplo, o Governo Federal da Alemanha e a Organisation of Economic Development and Co-operation (OECD) estabeleceram uma parceria visando a fomentar a educação empreendedora em instituições universitárias do leste alemão (OCDE, 2009). O documento "A Guiding Framework for Entrepreneurial Universities" aprofunda a discussão no sentido de tornar as universidades europeias um lócus empreendedor (OCDE, 2012). Também no Reino Unido, Estados Unidos, na China e leste asiático as iniciativas visando à promoção da educação empreendedora avançam de maneira significativa (World Bank, 2014). 


\section{Atos de Pesquisa em Educação - ISSN 1809-0354 \\ Blumenau, v. 13, n.2, p.312-334, mai./ago. 2018 \\ DOI: http://dx.doi.org/10.7867/1809-0354.2018v13n2p312-334}

No Brasil, a educação empreendedora vinculou-se inicialmente a cursos de Administração e áreas afins. Atualmente, a oferta de disciplinas e cursos específicos de empreendedorismo vem crescendo, devido a sua importância para a economia e para a sociedade. Para que possam despertar o comportamento empreendedor em seus aprendizes por meio de um ensino de qualidade, torna-se necessária a adoção de práticas educacionais capazes de aumentar a retenção e o envolvimento dos discentes no processo de educação.

Neste contexto, a análise das práticas educacionais adotadas em cursos de empreendedorismo no Brasil é importante, pois possibilita conhecer as lacunas existentes no processo de ensino-aprendizagem da área, incentiva os profissionais envolvidos na gestão acadêmica dos cursos a repensar suas práticas e, ainda, aponta práticas de sucesso que podem ser utilizadas em outras instituições, pois, conforme exposto por Nunes et al. (2015, p. 51), "enfatizar e valorizar essas boas práticas é uma forma de compartilhar e incentivar novas iniciativas".

Neste estudo, optou-se pela análise das práticas educacionais de um curso Sequencial - Minor em Empreendedorismo e Inovação - que apresentava um elevado índice de evasão, o que levou os responsáveis pela gestão acadêmica do curso a repensar o modelo e as atividades nele realizadas, com o objetivo de atrair e reter os alunos.

A partir das considerações ora apresentadas, o objetivo deste artigo foi definido como analisar as práticas educacionais adotadas para o ensino de empreendedorismo tomando como objeto de análise um curso sequencial de Empreendedorismo e Inovação.

Para tanto, foram realizadas entrevistas com os profissionais responsáveis pelo planejamento e implementação de mudanças relativas às práticas educacionais do curso. Posteriormente, o conteúdo das entrevistas foi analisado à luz dos indicadores propostos por Nunes et al. (2015), com o objetivo de discutir as potencialidades e limitações encontradas.

Quanto à estrutura, o artigo apresenta seis seções: além desta introdução, na seção 2 há a revisão bibliográfica sobre inovação na educação e indicadores de inovação em sala de aula; na seção 3 são definidos os procedimentos metodológicos; na seção 4, são apresentados os resultados e a discussão; enquanto que a seção 5 


\section{Atos de Pesquisa em Educação - ISSN 1809-0354 \\ Blumenau, v. 13, n.2, p.312-334, mai./ago. 2018 \\ DOI: http://dx.doi.org/10.7867/1809-0354.2018v13n2p312-334}

apresenta as considerações finais; e, finalizando, na seção 6 são apresentadas as referências bibliográficas.

\section{REFERENCIAL TEÓRICO}

\subsection{PRÁTICAS EDUCACIONAIS NO ENSINO DE EMPREENDEDORISMO}

O ensino de empreendedorismo se originou nos Estados Unidos, tendo sido o primeiro curso lecionado por Myles Mace, em 1947, na Escola de Administração de Harvard (KATZ, 2003 apud HENRIQUE; CUNHA, 2008; LOPES, 2010). O curso foi criado com o objetivo de oferecer qualificação para ex-combatentes da Segunda Guerra Mundial. Já, em 1953, Peter Drucker iniciou um curso de empreendedorismo na Universidade de Nova York, no qual inseriu, além de questões ligadas a pequenas empresas, discussões sobre inovação (LOPES, 2010).

Henrique e Cunha (2008) explicam que os cursos de empreendedorismo e a oferta de disciplinas sobre o tema se disseminaram lentamente nos Estados Unidos. De acordo com os autores, somente em 1970 houve aumento na oferta de cursos voltados para empreendedorismo nas universidades e escolas de negócios americanas, possivelmente motivado pela queda no número de empresas per capita.

O ensino do empreendedorismo se expandiu definitivamente na década de 1980, quando se constatou lacunas na educação em negócios. A década de 1980 também apresentou expansão de periódicos sobre o tema empreendedorismo (HENRIQUE; CUNHA, 2008).

No Brasil, o ensino do empreendedorismo é mais recente, se comparado com os Estados Unidos, em função de a industrialização ter apresentado crescimento exponencial apenas a partir da década de 1950 (HENRIQUE; CUNHA, 2008). O primeiro curso de empreendedorismo no Brasil, com foco na criação de negócios, foi introduzido pelo professor Ronald Degen, em 1981, em um curso de especialização de uma escola de Administração de Empresas de São Paulo. Mais tarde, a disciplina passou a ser ofertada também nos cursos de graduação, mestrado, doutorado e MBA.

De modo geral, o ensino do empreendedorismo não se originou nas escolas regulares como mais uma habilidade a ser desenvolvida nos alunos, tampouco em discussões filosóficas de educadores. Seu desenvolvimento ocorreu nos cursos 


\section{Atos de Pesquisa em Educação - ISSN 1809-0354 \\ Blumenau, v. 13, n.2, p.312-334, mai./ago. 2018 \\ DOI: http://dx.doi.org/10.7867/1809-0354.2018v13n2p312-334}

superiores de Ciências da Computação, Sistemas de Informação e Informática, disseminando-se também em cursos de Administração, nos quais tornou-se tema de pesquisas (LOPES, 2010).

Em 1993, o Conselho Nacional do Desenvolvimento Tecnológico e Científico (CNPq) criou o Programa SoftEx 2000 com o objetivo de aumentar a exportação de software brasileiro. Entre as estratégias adotadas buscou-se implementar a disciplina "Empreendimentos em Informática" em cursos de graduação em Ciência da Computação, Informática e Sistemas de Informação em instituições de ensino superior brasileiras. Segundo Dolabela (1998), em 1997 a disciplina havia sido implementada em 46 universidades brasileiras. O autor destaca que a metodologia didática da disciplina viabilizou um sistema de estímulo à criação de empresas de base tecnológica. Na área de administração, devido a diferenças existentes na formação de um administrador e de um empreendedor, nota-se receio por parte de professores de administração ao tratar do tema empreendedorismo (LOPES, 2010).

Lopes (2010) aponta a existência de distanciamento entre profissionais que se preocupam com a educação e profissionais que se preocupam em formar empreendedores. De acordo com o autor, há poucos estudos realizados em conjunto e poucos livros direcionados para as duas abordagens.

Uma questão recorrente nas discussões acerca do ensino de empreendedorismo se refere à possibilidade de ensinar alguém a ser um empreendedor. Conforme explica Lopes (2010), houve época em que as opiniões de autores da área se dividiam entre a ideia de que empreendedores nascem "prontos" e a de que seria possível formar empreendedores. Para Dolabela (2004), não é possível direcionar o aluno para que se torne um empreendedor empresarial, mas é possível direcioná-lo para se tornar empreendedor em sua forma de ser, para que seja empreendedor em qualquer atividade, mesmo sem constituir uma empresa. Neste caso, o que se busca é o desenvolvimento da mentalidade empreendedora, com foco na ação e realização humana.

Existem, na visão de Lopes (2010), dois tipos de propostas de ensino de empreendedorismo: 1) ensino de empreendedorismo com foco na criação de empresas; 2) ensino de empreendedorismo com foco no desenvolvimento de atitudes empreendedoras. 


\section{Atos de Pesquisa em Educação - ISSN 1809-0354 \\ Blumenau, v. 13, n.2, p.312-334, mai./ago. 2018 \\ DOI: http://dx.doi.org/10.7867/1809-0354.2018v13n2p312-334}

A educação empreendedora se caracteriza pela a utilização intensa de métodos de ensino capazes de promover a aprendizagem por meio da prática, o que a aproxima do conceito de aprendizagem vivencial apresentado por David A. Kolb (LOPES, 2010).

Lopes (2010) reforça a ligação entre o mundo real e a educação empreendedora, que se utiliza de recursos, estratégias e contextos com os quais os aprendizes se deparam em sua vida adulta, para criar uma aprendizagem significativa. A educação empreendedora também reforça "os vínculos com a comunidade, com os empreendedores e seus negócios, com os arranjos produtivos e todos que possam ser fontes de informação e de recursos" (LOPES, 2010, p. 30).

Em pesquisa sobre o empreendedorismo nas universidades brasileiras, realizada pelo instituto Endeavor e pelo Serviço Brasileiro de Apoio às Micro e Pequenas Empresas em 2014, nota-se que, nas instituições de ensino pesquisadas, há diversas disciplinas de empreendedorismo. Entretanto, essas disciplinas não são oferecidas em cursos específicos de empreendedorismo, mas em cursos de administração e economia e, em alguns casos, em cursos na área de ciências biológicas ou exatas. É comum que essas disciplinas sejam ofertadas no formato de eletivas, tendo, parte delas, um direcionamento teórico ou orientação para criação de um plano de negócios. Verifica-se na pesquisa a tendência de alteração no formato das disciplinas, com a redução do foco nos planos de negócios e adoção de conteúdos antes pouco tratados, como comportamento empreendedor e estímulo à inovação.

De acordo com o Instituto Endeavor (2012), as universidades estão buscando uma maior aproximação com o mercado, por meio de palestras sobre o tema com convidados e visitas a organizações locais. Esta iniciativa deve ser estimulada, uma vez que, quanto mais a academia se aproximar do mercado, maior será a segurança dos alunos ao iniciar um negócio (ENDEAVOR, 2012).

A tendência de alteração no formado das disciplinas e a aproximação com o mercado apontam a iniciativa de inserir inovações no processo de ensinoaprendizagem do empreendedorismo. Neste contexto, as subseções seguintes tratam de reflexões acerca da inovação na educação, de forma a compreender quais fatores podem contribuir para que as práticas adotadas para o ensino do empreendedorismo sejam efetivamente inovadoras. 


\section{Atos de Pesquisa em Educação - ISSN 1809-0354 \\ Blumenau, v. 13, n.2, p.312-334, mai./ago. 2018 \\ DOI: http://dx.doi.org/10.7867/1809-0354.2018v13n2p312-334}

\subsection{INOVAÇÃO NA EDUCAÇÃO}

Conforme explica Christensen (2012), os indivíduos aprendem de formas diferentes, em ritmos diferentes e por métodos diferentes. Entretanto, embora inúmeras pesquisas venham sendo realizadas no intuito de explicar a ideia de que as pessoas aprendem de modo diferente uma das outras, parece não haver o entendimento de quais são essas diferenças. O que se sabe é que tais diferenças podem ser codificadas no cérebro no nascimento ou baseadas em experiências vividas, especialmente nos primeiros anos de existência. Em sua obra, Christensen (2012, p. 1) apresenta uma indagação: "por que as escolas têm dificuldade para ensinar de maneira diferente se cada aluno aprende de um jeito diferente?".

O questionamento de Christensen (2012) aponta para a necessidade de inovação educacional, conceituada por Nunes et al. (2015, p. 54) como toda "ação pedagógica estruturada relativamente nova, que promove melhorias no processo de ensino-aprendizagem, considerando os diferentes contextos escolares, os interesses e necessidades dos alunos".

A inovação é um processo de "tradução, de decodificação da novidade pura em novidade aceitável, passível de ser aplicada, com o objetivo de melhorar aquilo que existe, de introduzir em dado contexto um aperfeiçoamento, um melhor saber, um melhor fazer e um melhor ser" (MITRULIS, 2002, p. 231).

Faz-se necessário distinguir inovação de invenção. As invenções se relacionam com a imaginação, constituindo-se em uma ideia promissora, que não tem necessariamente impacto social. Já a inovação inicia-se como uma invenção e se concretiza transformando pessoas e processos (FUNDAÇÃO VICTOR CIVITA, 2012).

A inovação no ensino superior é conceituada por Masetto (2003, p. 197) como "o conjunto de alterações que afetam pontos-chave e eixos constitutivos da organização do ensino universitário provocadas por mudanças na sociedade ou por reflexões sobre concepções intrínsecas à missão da Educação Superior".

De acordo com Masetto (2011, p. 599)

dentre as novas demandas que estão exigindo inovações em nossas aulas universitárias, podemos destacar para nossa reflexão quatro delas: a) Aula Universitária como espaço de pesquisa; b) como espaço de construção de conhecimento interdisciplinar; c) como espaço de desenvolvimento de aprendizagem e d) como espaço e tempo de uso das tecnologias de informação e comunicação. 
Segundo Masetto (2011), palestras, artigos e livros sobre inovação na educação sugerem a utilização de novas tecnologias de informação e comunicação na prática docente, utilização de computadores, trabalhos em grupo e ensino a distância.

Considerando a necessidade de inovação na educação discutida nesta subseção, a subseção a seguir apresenta indicadores de inovação em sala de aula, que podem contribuir para avaliação e melhoria das práticas adotadas por docentes em diferentes níveis educacionais.

\subsection{INDICADORES DE INOVAÇÃO EM SALA DE AULA}

A despeito da situação crítica da educação no Brasil, refletida nos resultados de avaliações nacionais e internacionais, Nunes et al. (2015) acreditam na existência de boas práticas e iniciativas voltadas para a busca de soluções inovadoras que devem ser valorizadas e compartilhadas com o objetivo de incentivar a busca por novas iniciativas. Em função disso, por meio de um grupo focal, os autores elaboraram critérios e indicadores para avaliação de práticas inovadoras na educação. O grupo foi composto por dezessete pessoas, "entre técnicos da SED, educadores, professores e especialistas com diferentes formações, experiências e backgrounds para a definição da inovação na educação e seus indicadores" (NUNES et al., 2015, p. 53).

Nunes et al. (2015) explicam que a avaliação não objetiva a qualificação ou desqualificação da prática, e sim a identificação de seus pontos fortes e fracos visando melhorias. Ademais,

[...] como maior benefício pode ser citada a visibilidade que os professores inovadores terão ao expor suas práticas e o conhecimento dos impactos na educação. Neste mesmo contexto, outros benefícios que podem ser citados com o mapeamento de boas práticas inovadoras se associa a possibilidade de que outros professores podem se sentir inspirados tanto para replicar as práticas quanto para idealizar e criar novas ideias a partir de suas realidades (NUNES et al., 2015, p. 52).

Os critérios essenciais que devem ser observados nas práticas educacionais, de acordo com a proposta de Nunes et al. (2015), são apresentados no Quadro 1. 


\section{Atos de Pesquisa em Educação - ISSN 1809-0354 \\ Blumenau, v. 13, n.2, p.312-334, mai./ago. 2018 \\ DOI: http://dx.doi.org/10.7867/1809-0354.2018v13n2p312-334}

Quadro 01 - Critérios e indicadores essenciais para a inovação na educação.

\begin{tabular}{|c|c|c|}
\hline Critério & Descrição & Indicadores \\
\hline 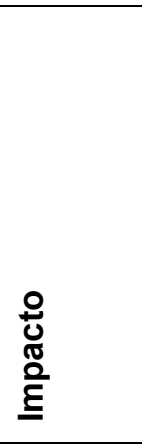 & $\begin{array}{l}\text { A ação pedagógica inovadora deve gerar mudanças } \\
\text { que resultem em melhorias reais para a educação. O } \\
\text { impacto refere-se ao efeito gerado após a execução da } \\
\text { prática educacional inovadora. Este deve ser } \\
\text { significativo e claramente percebido nos alunos e no } \\
\text { seu desempenho. }\end{array}$ & $\begin{array}{l}\text { Demonstra resultados } \\
\text { substanciais de melhoria na } \\
\text { aprendizagem; } \\
\text { Demonstra resultados } \\
\text { substanciais de melhoria do } \\
\text { fluxo escolar; } \\
\text { Demonstra resultados } \\
\text { substanciais no } \\
\text { desenvolvimento de } \\
\text { competências dos alunos, } \\
\text { considerando sua diversidade }\end{array}$ \\
\hline 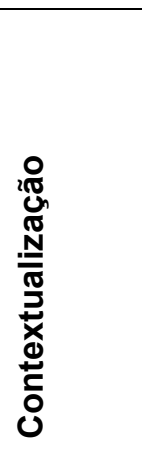 & $\begin{array}{l}\text { A prática educacional deve ser elaborada e executada } \\
\text { considerando as características do local e das pessoas } \\
\text { envolvidas no processo. A inovação só apresentará } \\
\text { resultados satisfatórios se estiver contextualizada. A } \\
\text { contextualização é um dos fatores mais determinantes } \\
\text { para o êxito de uma prática inovadora, e é um risco } \\
\text { tentar importar práticas sem as devidas adaptações } \\
\text { que respeitem as características culturais, sociais, } \\
\text { histórias e econômicas dos alunos e da } \\
\text { escola. }\end{array}$ & $\begin{array}{l}\text { Considera circunstâncias } \\
\text { sociais, econômicas e culturais } \\
\text { da escola, da comunidade e } \\
\text { da localidade. }\end{array}$ \\
\hline$\frac{\frac{\pi}{U}}{\frac{\mathscr{c}}{0 .}}$ & $\begin{array}{l}\text { A eficiência refere-se à racionalização dos recursos } \\
\text { (materiais, humanos, financeiros), de modo que se } \\
\text { obtenha o melhor resultado possível com a menor } \\
\text { quantidade de recursos. Ser eficiente na prática } \\
\text { educacional inovadora é empregar da melhor forma } \\
\text { possível os recursos disponíveis (CALEGARI e } \\
\text { PEREIRA, 2013). }\end{array}$ & $\begin{array}{l}\text { Fez bom uso dos recursos } \\
\text { (materiais e de estrutura) } \\
\text { disponíveis. }\end{array}$ \\
\hline $\begin{array}{l}\frac{0}{0} \\
\frac{\pi}{0} \\
\frac{0}{0} \\
\frac{0}{\frac{0}{0}} \\
\frac{.0}{2}\end{array}$ & $\begin{array}{l}\text { Aplicabilidade é a possibilidade de implementar a } \\
\text { prática em outro contexto fazendo as devidas } \\
\text { contextualizações. }\end{array}$ & $\begin{array}{l}\text { É aplicável em outras } \\
\text { realidades educacionais, } \\
\text { com as devidas adaptações. }\end{array}$ \\
\hline 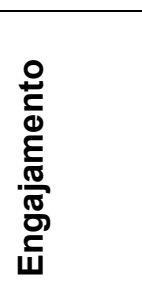 & $\begin{array}{l}\text { Engajamento na prática educacional inovadora é o } \\
\text { envolvimento e a interação entre os envolvidos: alunos, } \\
\text { professores, servidores, técnico administrativos e } \\
\text { direção da escola. O engajamento se reflete no } \\
\text { empenho com o qual os envolvidos participam da } \\
\text { prática. }\end{array}$ & $\begin{array}{l}\text { Promove o envolvimento ativo } \\
\text { de alunos, professores, } \\
\text { gestores e da comunidade } \\
\text { na prática inovadora. }\end{array}$ \\
\hline $\begin{array}{l}\frac{0}{0} \\
\frac{\pi}{0} \\
\frac{0}{0} \\
\frac{\pi}{0} \\
\frac{0}{0} \\
\frac{0}{0} \\
\frac{\pi}{0} \\
\stackrel{\Xi}{\underline{\Xi}}\end{array}$ & $\begin{array}{l}\text { A inovação não é um fim em si mesma, mas sim uma } \\
\text { forma de alcançar os objetivos da educação. A } \\
\text { inovação educacional deve ser orientada para } \\
\text { resultados, promovendo mudanças significativas no } \\
\text { contexto pedagógico e/ou escolar. }\end{array}$ & $\begin{array}{l}\text { Soluciona problemas dos } \\
\text { alunos, professores e da } \\
\text { escola como um todo. }\end{array}$ \\
\hline
\end{tabular}

Fonte: NUNES et al., 2015. 


\section{Atos de Pesquisa em Educação - ISSN 1809-0354 \\ Blumenau, v. 13, n.2, p.312-334, mai./ago. 2018 \\ DOI: http://dx.doi.org/10.7867/1809-0354.2018v13n2p312-334}

Nunes et al. (2015) explicam que existem outros critérios, além dos essenciais, considerados desejáveis. Esses critérios desejáveis possibilitam o aumento da qualidade das práticas educacionais, entretanto, sua ausência não a compromete. Os critérios desejáveis são apresentados no Quadro 2.

\begin{tabular}{|c|c|c|}
\hline Critério & Descrição & $\begin{array}{c}\text { Indicadores } \\
\end{array}$ \\
\hline 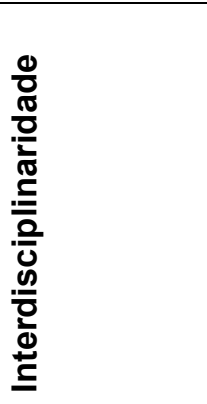 & $\begin{array}{l}\text { Na prática educacional inovadora } \\
\text { a interdisciplinaridade pode estar } \\
\text { presente na busca por integração } \\
\text { entre diferentes disciplinas, } \\
\text { conteúdos e abordagens. }\end{array}$ & $\begin{array}{l}\text { Integra diferentes conteúdos, } \\
\text { disciplinas e/ou áreas de } \\
\text { conhecimento; } \\
\text { Traz elementos novos gerando } \\
\text { novas formas de aprender e de } \\
\text { ensinar. }\end{array}$ \\
\hline 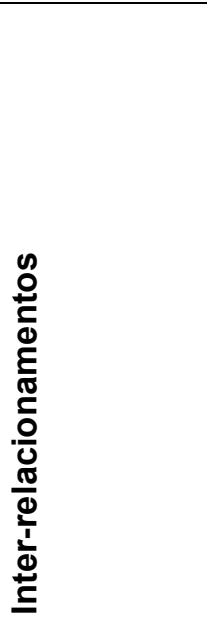 & $\begin{array}{l}\text { A diversidade de pessoas de fora } \\
\text { da escola envolvidas na prática } \\
\text { inovadora é altamente } \\
\text { enriquecedora. A inclusão de } \\
\text { colaboradores e organizações } \\
\text { além da escola aumenta a } \\
\text { complexidade da prática, pois há } \\
\text { potencialmente mais conflitos e } \\
\text { mais pessoas para gerenciar, } \\
\text { porém incrementa a capacidade } \\
\text { da rede para resolver problemas } \\
\text { multidimensionais, que não } \\
\text { podem ser reduzidos às } \\
\text { perspectivas particulares de } \\
\text { indivíduos (ORTEGA et al, 2007). }\end{array}$ & $\begin{array}{l}\text { Promove a participação de atores } \\
\text { externos à escola, formando } \\
\text { parcerias com outros professores, } \\
\text { escolas, comunidade ou outras } \\
\text { organizações. }\end{array}$ \\
\hline 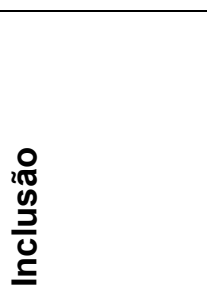 & $\begin{array}{l}\text { A inclusão em práticas } \\
\text { educacionais inovadoras refere- } \\
\text { se ao acolhimento } \\
\text { de todos os alunos, } \\
\text { independentemente de cor, } \\
\text { classe social e condições físicas } \\
\text { e psicológicas. }\end{array}$ & $\begin{array}{l}\text { Promove a aceitação e a } \\
\text { valorização das diferenças } \\
\text { individuais. }\end{array}$ \\
\hline
\end{tabular}

Fonte: NUNES et al., 2015.

A avaliação de práticas educacionais não deve ser binária, uma vez que uma prática educacional inovadora pode apresentar um critério em determinado grau. Para a identificação da presença de cada critério em uma prática educacional, Nunes et al. (2015) sugerem a utilização de uma escala Likert, conforme apresentado na Figura 1. 


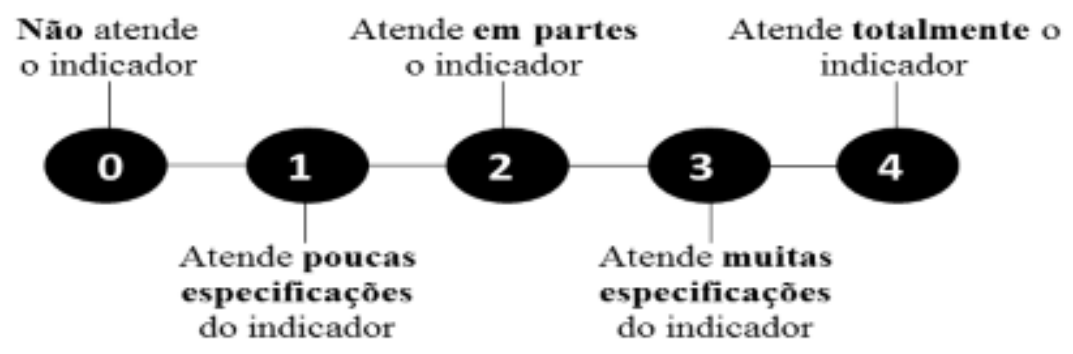

Figura 1 - Escala Likert para a avaliação dos indicadores.

Fonte: NUNES et al., 2015.

\section{PROCEDIMENTOS METODOLÓGICOS}

A presente pesquisa, cujo objetivo foi analisar as práticas educacionais adotadas para o ensino de empreendedorismo tomando como objeto de análise um curso sequencial de Empreendedorismo e Inovação, pode ser classificada, quanto à abordagem do problema, como qualitativa, que é aquela que considera que a relação entre o mundo objetivo e a subjetividade do sujeito não pode ser traduzida em números, pois há uma relação dinâmica entre eles. Por este motivo, não utiliza métodos e técnicas estatísticas (SILVA; MENEZES, 2001).

Quanto aos seus objetivos, esta pesquisa pode ser classificada como exploratória, que "visa proporcionar maior familiaridade com o problema com vistas a torná-lo explícito ou a construir hipóteses" (SILVA; MENEZES, 2001, p. 21). As pesquisas exploratórias costumam ser realizadas por meio de levantamento bibliográfico, entrevistas com pessoas que possuem experiência com o problema investigado e análise de exemplos, assumindo as formas de pesquisa bibliográfica e estudo de caso (SILVA; MENEZES, 2001).

Do ponto de vista dos procedimentos técnicos, trata-se de um estudo de caso, que "envolve o estudo profundo e exaustivo de um ou poucos objetos de maneira que se permita o seu amplo e detalhado conhecimento" (SILVA; MENEZES, 2001, p. 21), e que costuma ser adotado quando a questão da pesquisa é do tipo "como" e "por que" (YIN, 2001).

Na visão de Chizzoti (2006), estudo de caso é um

[...] estudo que envolve a coleta sistemática de informações sobre uma pessoa particular, um evento, uma atividade ou, ainda, um conjunto de relações ou processo social para melhor conhecer como são ou como operam 
em um contexto real e, tendencialmente, visa auxiliar tomadas de decisão, ou justificar intervenções, ou esclarecer por que elas foram tomadas ou implementadas e quais foram os resultados CHIZZOTI (2006, p. 135).

As novas práticas educacionais do curso Minor em Empreendedorismo e Inovação constituem a atividade foco deste estudo. Para alcançar o objetivo proposto, a coleta de dados foi realizada por meio de entrevistas com os profissionais responsáveis pelo planejamento e implementação das novas práticas educacionais adotadas no curso (dois professores do MBA em Gestão empresarial que também atuaram no Minor em Empreendedorismo e Inovação, que serão doravante denominados Entrevistado 1 e Entrevistado 2).

As entrevistas foram realizadas com o propósito de coletar informações que possibilitassem a compreensão de "como" e "por que" foram realizadas as mudanças no curso. Os dados obtidos por meio das entrevistas também foram utilizados como embasamento para avaliação, à luz dos indicadores de inovação em sala de aula propostos por Nunes et al. (2015), com o objetivo de discutir potencialidades e limitações das práticas adotadas, para que estas possam ser consideradas inovadoras.

As entrevistas foram realizadas por meio do Skype, um software de comunicação via internet, que permite chamadas de voz e vídeo entre pessoas em qualquer localidade.

\section{RESULTADOS E DISCUSSÃO}

O Curso Minor em Empreendedorismo e Inovação é um curso sequencial de complementação de estudos, com carga horária de 270 horas, e tem por objetivo oferecer educação empreendedora para estudantes de todos os cursos de graduação (major) de uma Instituição Federal de Ensino Superior (IFES). O Minor é realizado em um ambiente virtual de aprendizagem com encontros presenciais mensais, com duração de quatro horas cada.

Sua criação foi aprovada pelo Conselho Universitário em 27 de setembro de 2006 e seu currículo foi aprovado pelo Conselho Universitário em 29 de novembro de 2006. Inicialmente vinculado à Faculdade de Administração, Ciências Contábeis e Turismo, em 18 de dezembro de 2013, com a criação do Departamento de 
Empreendedorismo e Gestão na IFES estudada, as disciplinas do curso passaram a ser oferecidas por este departamento de ensino.

O Minor em Empreendedorismo e Inovação é realizado na modalidade semipresencial, portanto, as atividades realizadas pelos discentes são divididas entre atividades a distância e atividades presenciais. A carga horária do curso é de 270 horas, divididas em sete disciplinas obrigatórias, conforme apresentado no Quadro 3.

Quadro 03 - Disciplinas e carga horária do Minor em Empreendedorismo e Inovação
\begin{tabular}{|c|c|}
\hline Disciplina & Carga horária \\
\hline Criatividade e atitude empreendedora & $60 \mathrm{~h}$ \\
\hline Estratégia e marketing para empreendedores & $30 \mathrm{~h}$ \\
\hline Finanças para empreendedores & $30 \mathrm{~h}$ \\
\hline Gestão de pessoas & $30 \mathrm{~h}$ \\
\hline Gestão empreendedora por processo & $30 \mathrm{~h}$ \\
\hline Técnicas de comunicação e negociação & $30 \mathrm{~h}$ \\
\hline Plano de empreendimento & $30 \mathrm{~h}$ \\
\hline
\end{tabular}

FONTE: elaborado pelas autoras, com base no manual do curso.

Em consideração ao exposto por Lopes (2010) em relação às propostas de ensino de empreendedorismo existentes, nota-se que o curso estudado oferece disciplinas voltadas para as duas abordagens apresentadas pelo autor: ensino de empreendedorismo com foco na criação de empresas e ensino de empreendedorismo com foco no desenvolvimento de atitudes empreendedoras.

Destaca-se a relevância da oferta de um curso totalmente voltado para o ensino do empreendedorismo, o que difere do cenário apresentado pelo Instituto Endeavor e pelo Serviço Brasileiro de Apoio às Micro e Pequenas Empresas, que apontou, em 2014, que as disciplinas de Empreendedorismo não eram oferecidas em cursos específicos de Empreendedorismo, mas em cursos como Administração e Economia.

\subsection{NOVAS PRÁTICAS EDUCACIONAIS DO CURSO MINOR - EMPREENDEDORISMO E INOVAÇÃO}

De acordo com o Entrevistado 1, o diagnóstico da necessidade de reformulação das práticas educacionais do curso ocorreu a partir de avaliações do curso e de cada uma das disciplinas que o compõem. O Entrevistado 2 acrescentou que as avaliações do curso ocorreram por meio de uma pesquisa com alunos ingressantes no ano de 


\title{
Atos de Pesquisa em Educação - ISSN 1809-0354 \\ Blumenau, v. 13, n.2, p.312-334, mai./ago. 2018 \\ DOI: http://dx.doi.org/10.7867/1809-0354.2018v13n2p312-334
}

2014. Na ocasião também havia sido identificado um alto índice de evasão e reclamações relativas às atividades realizadas.

O planejamento das alterações no curso teve início em dezembro de 2014 e as novas práticas começaram a ser implementadas em março de 2015. O Entrevistado 2 explicou que as novas práticas adotadas no curso foram elaboradas com base nas teorias da Andragogia ${ }^{1}$ e Pedagogia ${ }^{2}$ e na experiência em Educação a Distância dos profissionais envolvidos.

Todas as atividades presenciais e a distância do curso sofreram algum tipo de alteração. A primeira iniciativa foi em relação à duração do curso. A carga horária de 270 horas foi mantida, mas as disciplinas foram reorganizadas em bimestres e o curso passou a ter a duração de um ano, o que corresponde à metade da duração anterior. Conforme exposto pelo Entrevistado 2, em cada disciplina passaria a ser elaborada uma parte do Plano de Empreendimento (PLEM), que era realizado ao final do curso. As provas on line ao final das disciplinas foram substituídas por um quiz abordando o conteúdo da disciplina.

Outra mudança citada pelos entrevistados se refere aos encontros presenciais, que passaram a ser mais práticos:

\begin{abstract}
Eles eram muito descolados das atividades na plataforma e acabavam sendo palestras e provões. Alteramos isso da seguinte forma: 1) na primeira semana da primeira disciplina os alunos, de diferentes cursos, se organizariam em grupos de trabalho e seguiriam juntos até o final do curso. Para que todos pudessem se conhecer, eles foram divididos por turmas e nelas foram feitas dinâmicas de apresentação; 2) após definido o grupo multidisciplinar, os alunos deveriam definir qual problema iriam resolver. Essa atividade ocorreu na plataforma, em um fórum de discussão mediado pelo tutor; 3) definido o grupo e definido o negócio ou segmento de mercado, as disciplinas seguintes se desdobraram no desenvolvimento do plano de empreendimentos, onde a cada disciplina foram sendo discutidos assuntos referentes às estratégias de marketing do negócio, o mapeamento dos principais processos, a estruturação da equipe de trabalho e etc. Em todas as etapas os encontros presenciais se tornaram fundamentais. Primeiro, porque servia para o grupo se encontrar e discutir. Além disso, era dividido em duas etapas: de manhã uma aula mais expositiva sobre o conteúdo e na segunda parte uma dinâmica onde os grupos desenvolviam parte do plano de empreendimento referente a disciplina que estava sendo ministrada (ENTREVISTADO 1).
\end{abstract}

\footnotetext{
${ }^{1} \mathrm{~A}$ andragogia se refere a um modelo educacional voltado para adultos (NOGUEIRA, 2014).

${ }^{2}$ A pedagogia "é um campo de conhecimentos sobre a problemática educativa na sua totalidade e historicidade e, ao mesmo tempo, uma diretriz orientadora da ação educativa" (LIBÂNEO, 2001, p. 6).
} 


\section{Atos de Pesquisa em Educação - ISSN 1809-0354 \\ Blumenau, v. 13, n.2, p.312-334, mai./ago. 2018}

DOI: http://dx.doi.org/10.7867/1809-0354.2018v13n2p312-334

Após implementação das práticas, foi observada redução na evasão, melhoria dos Planos de Empreendimento apresentados, aumento na procura pelo curso e a iniciativa de uma ex-aluna em se voluntariar para trabalhar no curso.

$\mathrm{Na}$ Figura 2, é apresentado um resumo do processo de planejamento e implementação das novas práticas inseridas no curso.

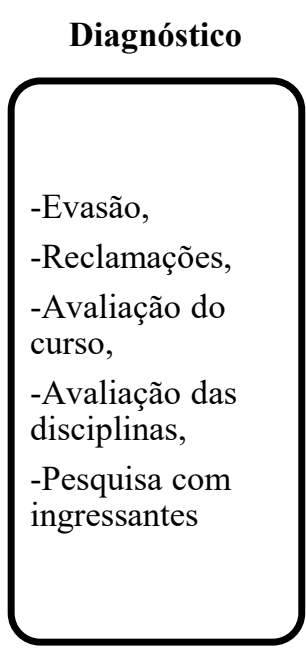

2014
Planejamento

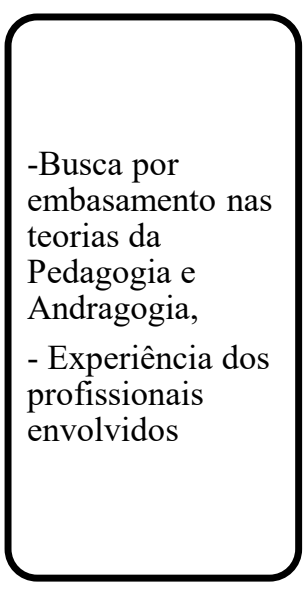

2014

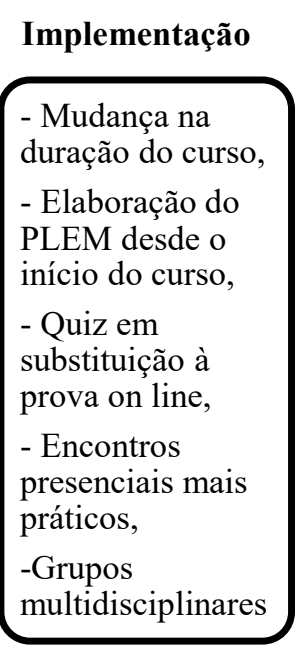

2015
Feedback

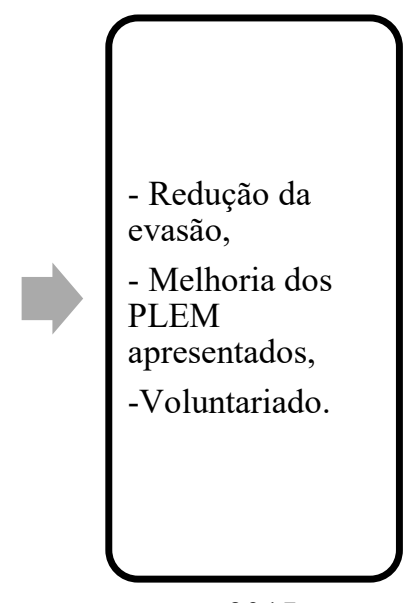

2015

Figura 2 - Processo de planejamento e implementação das novas práticas do Minor Fonte: Elaborado pelas autoras

\subsection{AVALIAÇÃO DAS PRÁTICAS EDUCACIONAIS DO CURSO MINOR EM EMPREENDEDORISMO E INOVAÇÃO}

Após compreensão do processo de planejamento e implementação das práticas educacionais adotadas no curso, além do diagnóstico da necessidade de mudança e feedback após implementação das novas práticas, os dados obtidos nas entrevistas foram utilizados como embasamento para avaliação, à luz dos indicadores propostos por Nunes et al. (2015), que são apresentadas na sequência.

a) Critério 1: Impacto

Em relação às melhorias para a educação geradas a partir das novas práticas adotadas, de acordo com o Entrevistado 1, podem ser observados: redução na 
evasão, aumento da participação dos alunos e melhoria nos planos de empreendimentos apresentados. Já de acordo com o Entrevistado 2, é possível observar melhorias na satisfação dos alunos e aumento na procura pelo curso. Ambos os entrevistados citaram o exemplo de uma ex-aluna que se voluntariou para trabalhar no curso. O Entrevistado 2 acredita não ter condições de mensurar melhorias na aprendizagem, por ter lecionado apenas uma disciplina no modelo antigo.

A partir das considerações apresentadas e baseado nos indicadores propostos por Nunes et al. (2015), no que se refere ao critério "impacto", as práticas educacionais adotadas no curso Minor - Empreendedorismo e Inovação atendem muitas especificações dos indicadores: melhoria do fluxo escolar por meio da redução de evasão e aumento da procura pelo curso; desenvolvimento de competência dos alunos por meio de melhorias nos planos de empreendimento apresentados. Faz-se necessária a adoção de meios de mensuração da aprendizagem, para avaliar se mudanças ocorridas no curso proporcionaram melhoria na aprendizagem.

\section{a) Critério 2: Contextualização}

Quanto ao critério contextualização, o Entrevistado 2 considera difícil particularizar aspectos do púbico alvo, uma vez que o Minor é oferecido para alunos de todos os cursos de graduação e para servidores. Neste sentido, o Entrevistado 2 relatou que levou em consideração a diversidade, não particularidades. Alunos da área de gestão possuem maior conhecimento relativo aos temas tratados no curso, enquanto que alunos de outras áreas poderiam ter maiores dificuldades. Isso foi considerado durante a elaboração das novas práticas, para que o objetivo de aprendizagem pudesse ser alcançado.

De acordo com o Entrevistado 1, alguns aspectos próprios da natureza de um curso sequencial foram pensados com cuidado:

\footnotetext{
como integrar alunos de diferentes formações? (trabalho em equipe, onde cada um contribui com o conhecimento específico da sua área); 2) como tornar os encontros presenciais, ministrados aos sábados, atraentes? (com atividades mais dinâmicas, práticas e relacionadas aos conteúdos trabalhados na plataforma); 3) Como deixar a plataforma mais amigável? (criando uma identidade visual e pensando em atalhos que facilitassem a acessibilidade para as atividades e conteúdos); 4) apresentar os conteúdoschave dos módulos das disciplinas a partir de vídeos curtos (2-8 minutos) e a elaboração de materiais complementares (Power points, reportagens, vídeos e resumos) (ENTREVISTADO 1).
} 
Em função da elaboração e implementação de práticas educacionais que consideram a diversidade de formação dos alunos do curso e em função da gestão dos recursos apresentadas pelos entrevistados (características econômicas da instituição de ensino), conclui-se que as modificações ocorridas no Minor atendem em partes o indicador, pelo fato de não ter sido citada qualquer iniciativa relacionada às características sociais e históricas dos alunos e da instituição.

b) Critério 3: Eficiência

Em relação à utilização dos recursos disponíveis, o Entrevistado 1 esclareceu que o curso não possui recursos próprios, contando com o apoio de professorestutores que atuam na pós-graduação do Departamento de Empreendedorismo e Gestão e de dois professores colaboradores. Por possuir um quadro de professores pequeno, o Departamento de Empreendedorismo e Gestão oferece o Minor - que já foi viabilizado por meio de parceria com o CEDERJ e a UAB - com o desafio de gerir poucos recursos financeiros e humanos.

O Entrevistado 1 acrescentou, ainda, quanto ao desafio de oferecer o curso com poucos recursos, que os profissionais envolvidos seguem o que ensinam: "quando temos um problema, temos também uma oportunidade".

O Entrevistado 2 considera não haver necessidade de muitos recursos e explica que é solicitado aos próprios alunos que levem material para os encontros presenciais. Além disso, há dois alunos do Major que atuam como monitores nos encontros presenciais e ajudam a elaborar os materiais.

Conclui-se, portanto, que as práticas adotadas no Minor atentem totalmente este indicador, por fazer bom uso dos recursos disponíveis para o curso, buscando a obtenção do melhor resultado possível com recursos limitados, aplicando os próprios conceitos ensinados no curso para enfrentar possíveis limitações e dificuldades referentes a este aspecto.

c) Critério 4: Aplicabilidade

O Entrevistado 2 considera que é possível aplicar as práticas adotadas no Minor em outras realidades educacionais, desde que sejam feitas as devidas contextualizações, conforme sugerido por Nunes et al. (2015). Essa possibilidade pode ser justificada pelo fato de as mudanças terem sido orientadas por princípios 
pedagógicos e andragógicos, conforme colocado pelo Entrevistado 2. Assim, as novas práticas atendem totalmente este indicador, por possibilitarem a implementação em outros contextos, com as adaptações necessárias.

d) Critério 5: Engajamento

Segundo o Entrevistado 1,

[...] o curso Minor hoje traz um diálogo melhor com os alunos, visto que integra diferentes ferramentas para apresentar os conteúdos, integra os diferentes conhecimentos deles e está sempre atento aos resultados das avaliações das disciplinas e na opinião dos alunos, em um processo constante de busca pela qualidade (ENTREVISTADO 1).

O Entrevistado 2 relatou ter sido previsto o envolvimento dos alunos no desenvolvimento das novas práticas educacionais do curso.

Não foram citadas, apenas, atividades com o envolvimento da comunidade. Dessa forma, considera-se que as práticas adotadas atendem muitas especificações deste indicador, em função do envolvimento de alunos, professores e gestores nas práticas.

e) Critério 6: Intencionalidade

As novas práticas inseridas no curso possibilitaram a redução da evasão, um dos problemas diagnosticados pela equipe. Também possibilitaram a melhorias dos planos de empreendimentos elaborados pelos discentes. Dessa forma, a partir dos indicadores propostos por Nunes et al. (2015), verifica-se que as práticas inseridas no curso atendem totalmente este indicador, por possibilitarem a solução de problemas identificados em momento anterior à sua adoção.

f) Critério 7: Interdisciplinaridade

As práticas adotadas no Minor passaram a integrar as disciplinas que 0 compõem por meio da elaboração de uma parte do PLEM a cada disciplina. Considera-se, portanto, que há o atendimento total deste indicador, uma vez que, por meio das práticas adotadas, diferentes conteúdos e disciplinas são integrados.

g) Critério 8: Inter-relacionamentos 
Em relação à participação de atores externos à instituição e parcerias com outras instituições, professores, comunidade e outras organizações, o Entrevistado 1 relatou a participação de empreendedores como palestrantes nos encontros presenciais: "as parcerias sempre reforçam o nosso trabalho e evitam que os encontros presenciais sejam sempre com os mesmos professores".

Já de acordo com o Entrevistado 2, alguns produtos do PLEM foram patenteados por uma pessoa externa ao curso. Há também a participação de professores de outras instituições nas bancas de avaliação dos PLEM, e existe a intenção de convidar gestores e caça talentos para comparecerem às bancas finais, com o objetivo de que estes possam conhecer o trabalho dos alunos.

Considera-se, portanto, que as práticas adotadas no curso atendem totalmente este indicador, por promoverem a participação de atores externos à instituição.

\section{h) Critério 9: Inclusão}

Em relação à aceitação e à valorização das diferenças individuais, conforme colocado anteriormente, o curso conta com a participação de alunos de diferentes cursos de graduação, além de servidores da universidade. Dessa forma, ao levar em consideração essa diversidade, conforme exposto pelos entrevistados, as práticas adotadas atendem totalmente este indicador.

O Quadro 4 apresenta um resumo da avaliação das práticas educacionais do curso Minor em Empreendedorismo e Inovação, a partir dos indicadores propostos por Nunes et al. (2015).

Quadro 4: resumo da avaliação das práticas educacionais do curso Minor -Empreendedorismo e inovação

\begin{tabular}{|c|c|}
\hline \multicolumn{2}{|c|}{ Critérios e Indicadores Essenciais para a inovação na } \\
educação
\end{tabular}


Atos de Pesquisa em Educação - ISSN 1809-0354

Blumenau, v. 13, n.2, p.312-334, mai./ago. 2018

DOI: http://dx.doi.org/10.7867/1809-0354.2018v13n2p312-334

\begin{tabular}{|c|c|}
\hline $\begin{array}{c}\text { Inter- } \\
\text { relacionamentos }\end{array}$ & Atende totalmente o indicador \\
\hline Inclusão & Atende totalmente o indicador \\
\hline
\end{tabular}

Fonte: elaborado pelas autoras, com base em Nunes et al. (2015)

\section{CONSIDERAÇÕES FINAIS}

Quanto ao objetivo dessa pesquisa que foi 0 de analisar as práticas educacionais adotadas para o ensino de empreendedorismo tomando como objeto de análise um curso sequencial de Empreendedorismo e Inovação, conclui-se que as novas práticas adotadas atendem a maior parte dos indicadores propostos por Nunes et al. (2015), o que contribui para instituições que oferecem cursos na área de empreendedorismo e que passam pelo processo de reformulação de suas práticas pedagógicas. Contribui, ainda, para a própria instituição analisada, por possibilitar a identificação dos pontos fortes e fracos das novas práticas adotadas, visando a melhorias futuras.

O estudo aponta aspectos que devem ser repensados, para que todos os indicadores sejam atendidos: faz-se necessário considerar aspectos sociais e históricos dos alunos e da instituição, promover o envolvimento da comunidade e buscar medidas de avaliação da aprendizagem gerada a partir das práticas adotadas.

Uma das medidas que podem ser adotadas pelos responsáveis pela gestão acadêmica do curso estudado, como forma de atender ao critério "engajamento" cujos indicadores não são atendidos totalmente com as práticas adotadas - é a maior aproximação com o mercado e visitas a instituições locais, conforme sugerido pelo Instituito Endeavor (2012).

Como proposições para novos estudos, sugerem-se entrevistas com alunos, responsáveis pela gestão acadêmica do curso e demais agentes envolvidos nas práticas.

\section{LANA CRISTINA OLIVEIRA}

Mestre em Administração pela Universidade Federal Fluminense. Pós-graduada em Planejamento, Implementação e Gestão da EAD pelo LANTE/UFF. Tutora a distância no curso de Engenharia de Produção do CEDERJ. Professora do curso de Ciências Contábeis da Associação Educacional Dom Bosco. 


\section{SANDRA REGINA HOLANDA MARIANO}

Professora associada ao Departamento de Empreendedorismo e Gestão da Faculadade de Administração e Ciências Contábeis, Universidade Federal Fluminense (UFF). É coordenadora do Projeto OportUnidad no Brasil, financiado pela European Comission (EC) e consultura de empresas.

\section{REFERÊNCIAS BIBLIOGRÁFICAS}

CHIZZOTTI, A. Pesquisa Qualitativa em Ciências Humanas e Sociais. Petrópolis: Vozes, 2006.

CHRISTENSEN, Clayton M. Inovação na Sala de Aula. Como a inovação disruptiva muda a forma de aprender. Bookman, Porto Alegre, 2011.

DESCHAMPS, Eduardo; CALEGARI, Diego. In. EHLERS, Ana Cristina da Silva Tavares; TEIXEIRA, Clarissa Stefani; SOUZA, Marcio Veira de. Educação fora da caixa: tendência para a educação no século XXI . Florianópolis, SC, Bookess, 2015.

DOLABELA, Fernando. Pedagogia Empreendedora. Revista de Negócios, Blumenau, v. 9, n. 2, p. 127-130, abril/junho 2004.

DOLABELA, Fernando $C$. O ensino universitário de criação de empresas na área de software - A disciplina "Empreendimentos em Informática" do Programa SoftEx 2000. Recife. 1998. Disponível em: http://www.di.ufpe.br/ genesis/ensino.html. Acesso em: 21.Jul.2016.

ENDEAVOR. Empreendedorismo nas Universidades Brasileiras 2012. Endeavor Brasil, 2012.

ENDEAVOR; SEBRAE. Empreendedorismo nas Universidades Brasileiras 2014. Endeavor Brasil e Sebrae, 2014.

FUNDAÇÃO VICTOR CIVITA. Caminhos para inovar. Fundação Victor Civita, Edição Especial, São Paulo, 2012

HENRIQUE, Daniel Christian; CUNHA, Sieglinde Kindl. Práticas didáticopedagógicas no ensino de empreendedorismo em cursos de graduação e pósgraduação nacionais e internacionais. RAM - Revista de Administração Mackenzie. Volume 9, n. 5, 2008, p. 112-136.

HINCKEL, Nágila Cristina. A escola e as competências para o século XXI. In. EHLERS, Ana Cristina da Silva Tavares; TEIXEIRA, Clarissa Stefani; SOUZA, Marcio Veira de. Educação fora da caixa : tendência para a educação no século XXI . Florianópolis, SC, Bookess, 2015

INCE, Martin; O'Leary, John; Quacquarelli, Nunzio; Sowter; Bem. Top Universities Guide 2017. London: QS Quacquarelli Symonds Limited. Disponível em: http://www.qs-asia.com/main/files/TUG_Full_2017.pdf. Acesso em 02 out 2017. 
LIBÂNEO, José Carlos. Pedagogia e pedagogos: inquietações e buscas. Educar em Revista, n. 17, p. 153-176, 2001.

LOPES, Rose Mary. Educação Empreendedora: conceitos, modelos e práticas. Rio de Janeiro, Elsevier; São Paulo, SEBRAE, 2010.

MALHOTRA, Naresh. Pesquisa de Marketing. Uma orientação aplicada. $3^{\mathrm{a}}$ Edição, Porto Alegre: Bookman, 2001.

MASETTO, Marcos. Inovação na Educação Superior. Interface - Comunic., Saúde, Educ., v.8, n.14, p.197-202, set.2003-fev. 2004.

MASETTO, Marcos. Inovação na aula universitária: espaço de pesquisa, construção de conhecimento interdisciplinar, espaço de aprendizagem e tecnologias de comunicação. PERSPECTIVA, Florianópolis, v. 29, n. 2, 597-620, jul./dez. 2011.

MITRULIS, Eleny. Ensaios de inovação no ensino médio. Cadernos de Pesquisa, n. 116, julho/ 2002 Cadernos de Pesquisa, n. 116, p. 217-244, julho/ 2002.

NOGUEIRA, Sónia Mairos. A andragogia: que contributos para a prática educativa?. Linhas, v. 5, n. 2, 2004.

NUNES, Carolina Schmitt; NAKAYAMA, Marina Keiko; SILVEIRA, Ricardo Azambuja; STEFANI, Clarissa; CALEGARI, Diego. Critérios e Indicadores de Inovação na Educação. In. EHLERS, Ana Cristina da Silva Tavares; TEIXEIRA, Clarissa Stefani; SOUZA, Marcio Veira de. Educação fora da caixa : tendência para a educação no século XXI . Florianópolis, SC, Bookess, 2015.

OCDE. A Guiding Framework for Entrepreneurial Universities. 2012. Disponível em: https://www.oecd.org/site/cfecpr/EC-

OECD\%20Entrepreneurial\%20Universities\%20Framework.pdf . Acesso em: 21.Jul.2016.

OCDE. Universities, innovation and entreprene Urship criteria and examples of good practice. Berlin. 2009. Disponível em: https://www.oecd.org/cfe/leed/43201452.pdf. Acesso em: 21.Jul.2016.

PISA. Organisation for Economic Co-operation and Development (OECD), 2015. Disponível em: www.oecd.org/pisa/. Acesso em 02 out 2017.

SILVA, Edna Lúcia da; MENEZES, Estera Muszkat. Metodologia da pesquisa e elaboração de dissertação. $3^{\mathrm{a}}$ ed. UFSC/PPGEP/LED, Florianópolis, 2001.

STE-Departamento de Empreendedorismo e Gestão-Universidade Federal Fluminense. Relatório Anual de Atividades - 2015. Niterói. 2016. Disponível em: http://empreendedorismouff.net.br/relatorio-anual-de-atividades-2015/. Acesso em: 21.jul.2016. 
The National Centre for Entrepreneurship in Education (NCEE). The Entrepreneurial University: From Concept To Action, Coventry, UK. 2013. Disponível em: http://ncee.org.uk/wp-content/uploads/2014/06/From-Concept-To-Action.pdf. Acesso em: 21Jul.2016.

The World Bank. Entrepreneurship Education and Training Programs around the World. Washington. 2014.2 Disponivel em: https://openknowledge.worldbank.org/bitstream/handle/10986/18031/978146480202 7.pdf?sequence=1. Acesso em: 21.Jul.2016.

YIN, Robert K. Estudo de caso: planejamento e métodos. 2.ed.- Porto Alegre: Bookman, 2001. 